\title{
Influence of Yttria-Stabilized Zirconia on Microstructure and Electrical Properties of Doped Lanthanum Gallate
}

\author{
Talita Gishitomi Fujimoto ${ }^{a *}$, Shirley Leite Reis ${ }^{a}$, Eliana Navarro dos Santos Muccillo ${ }^{a}$ \\ ${ }^{a}$ Instituto de Pesquisas Energéticas e Nucleares, São Paulo, SP, Brasil
}

Received: January 19, 2019; Revised: April 29, 2019; Accepted: June 18, 2019

\begin{abstract}
Lanthanum gallate with partial substitutions for strontium and magnesium shows higher ionic conductivity than traditional ionic conductors such as yttria-stabilized zirconia (8YSZ), and has been considered for application as solid electrolyte and electrode in Solid Oxide Fuel Cells operating at intermediate temperatures $\left(500-700^{\circ} \mathrm{C}\right)$. Parallel to the development of new solid electrolytes, improvement of the already known electrolytes has been one goal. In this work, the effects of adding 8 YSZ to $\mathrm{La}_{0.9} \mathrm{Sr}_{0.1} \mathrm{Ga}_{0.8} \mathrm{Mg}_{0.2} \mathrm{O}_{3-\delta}$ (LSGM), on the microstructure and electrical performance were investigated. Compound electrolytes consisting of up to $20 \mathrm{wt} . \% 8 \mathrm{YSZ}$ were prepared by solid state reactions. Sintered pellets with up to $10 \mathrm{wt} . \% 8 \mathrm{YSZ}$ achieved near full density after sintering at $1450^{\circ} \mathrm{C}$ and reduction in the fraction of impurity phases. Addition of $8 Y S Z$ promoted grain growth to LSGM. The higher ionic conductivity was obtained for $1 \mathrm{wt} \%$ 8YSZ addition with slight decrease of the apparent activation energy.
\end{abstract}

Keywords: Lanthanum gallate, yttria-stabilized zircônia, microstructure, ionic conductivity.

\section{Introduction}

Oxide-ion conductors with perovskite structure based on doped lanthanum gallate find application as solid electrolyte and electrodes in Solid Oxide Fuel Cells (SOFCs). These electrochemical devices have received considerable attention as clean-energy production systems, with several advantages, such as low noise, fuel flexibility, low emissions, high efficiency and cell scalability, compared to conventional energy conversion engines ${ }^{1,2}$.

Since the pioneering works of Ishihara ${ }^{3}$ and Feng ${ }^{4}$, ceramic conductors consisting of lanthanum gallate with partial substitutions for strontium and magnesium in the A- and B-sites, respectively, of the perovskite structure ( $\mathrm{La}_{1}$ ${ }_{\mathrm{x}} \mathrm{Sr}_{\mathrm{x}} \mathrm{Ga}_{1-\mathrm{y}} \mathrm{Mg}_{\mathrm{y}} \mathrm{O}_{3-\delta}$, with $0.1 \leq \mathrm{x}, \mathrm{y} \leq 0.2$ ) have been thoroughly investigated, due to their high ionic conductivity along with wide electrolytic domain, as described in recent reviews ${ }^{5,6}$.

Among the studied compositions, the $\mathrm{La}_{0.9} \mathrm{Sr}_{0.1} \mathrm{Ga}_{0.8} \mathrm{Mg}_{0.2} \mathrm{O}_{3-\delta}$ exhibits distorted perovskite structure with orthorhombic symmetry, high ionic conductivity and relatively low fraction of impurity phases ${ }^{1,2,7,8}$.

Recently, the need to improve the physical properties of these ceramic solid electrolytes has led to the investigation of more complex systems constituted by two solid electrolytes (compound or composite electrolytes). In this context, few studies may be found related to doped lanthanum gallates. Addition of small amounts of $\mathrm{La}_{0.8} \mathrm{Sr}_{0.2} \mathrm{Ga}_{0.8} \mathrm{Mg}_{0.2} \mathrm{O}_{3-\delta}$ to $\mathrm{Ce}_{0.9} \mathrm{Gd}_{0.1} \mathrm{O}_{1.95}$ resulted in an expanded electrolytic domain towards low oxygen partial pressures ${ }^{9}$. Improvement on the ionic conductivity was observed by addition of $9 \mathrm{~mol} \%$ yttria-stabilized zirconia to $\mathrm{La}_{0.9} \mathrm{Sr}_{0.1} \mathrm{Ga}_{0.8} \mathrm{Mg}_{0.2} \mathrm{O}_{2.85}{ }^{10}$. Unit
SOFCs with composite electrolytes of $\mathrm{La}_{0.85} \mathrm{Sr}_{0.15} \mathrm{Ga}_{0.8} \mathrm{Mg}_{0.2} \mathrm{O}_{2.825}$ and $\mathrm{Ce}_{0.85} \mathrm{Sm}_{0.15} \mathrm{O}_{1.925}$ did not show significant enhancement compared to the single electrolyte component cell ${ }^{11}$.

In this work a systematic study of LSGM - 8YSZ compound electrolytes was carried out, aiming to correlate the microstructure and the ionic conductivity.

\section{Experimental}

\subsection{Materials}

Lanthanum oxide, $\mathrm{La}_{2} \mathrm{O}_{3}(99.9 \%$, Alfa Aesar, USA), gallium oxide, $\mathrm{Ga}_{2} \mathrm{O}_{3}(99.99 \%$, Alfa Aesar, USA), strontium carbonate, $\mathrm{SrCO}_{3}(99.99 \%$, Alfa Aesar, USA) and $\mathrm{MgO}$ (P.A., Merck, German) were used as starting materials to synthesize the composition $\mathrm{La}_{0.9} \mathrm{Sr}_{0.1} \mathrm{Ga}_{0.8} \mathrm{Mg}_{0.2} \mathrm{O}_{3-\delta}$. Commercial 8YSZ (99.6\%, Tosoh, Japan) was used to prepare compound electrolytes of (100-x)LSGM + x8YSZ with $\mathrm{x}=0,1,10$ and 20 wt.\%.

\subsection{Preparation methods}

LSGM was synthesized by the solid state reaction method. At first, lanthanum oxide precursor was heat treated at $1000^{\circ} \mathrm{C}$ for $3 \mathrm{~h}$. Stoichiometric amounts of the starting materials were mixed together, calcined at $1250^{\circ} \mathrm{C}$ for $4 \mathrm{~h}$ and desagglomerated in an agate mortar with pestle. This procedure was repeated twice amounting $12 \mathrm{~h}$ of calcination. Afterwards, the powder mixture was attrition milled with zirconia media and isopropyl alcohol for $1 \mathrm{~h}$, followed by drying at $40^{\circ} \mathrm{C}$. This procedure was found to produce dense specimens after sintering at $1450^{\circ} \mathrm{C}^{12}$. 
Compound solid electrolytes were prepared by mixing together desired amounts of the synthesized LSGM and commercial $8 Y S Z$ in agate mortar with isopropyl alcohol until drying. The mixtures were pressed (50 MPa) into pellets in a stainless steel dye. Sintering of green compacts was carried out in a resistive furnace (Lindberg BlueM) in air at temperatures ranging from 1350 to $1450^{\circ} \mathrm{C}$ for $4 \mathrm{~h}$.

\subsection{Characterization methods}

The crystalline structure of powder mixtures and sintered pellets was evaluated by X-ray diffraction, XRD (BrukerAXS, D8 Advance) in the $20^{\circ} \leq 2 \theta \leq 80^{\circ}$ angular range with $0.05^{\circ}$ step size and $2 \mathrm{~s}$ counting time, using Ni-filtered $\mathrm{Cu} \mathrm{K}_{\alpha}$ radiation $(\lambda=1.5405 \AA)$. Identification of crystalline phases was accomplished by comparing the experimental diffraction patterns with those of powder diffraction files (ICSD). The apparent density $(\rho)$ of sintered specimens was determined by the water immersion method. The relative density $\left(\rho_{\mathrm{r}}\right)$ was calculated from:

$$
\rho_{r}=\left(\frac{\rho}{\rho_{c}}\right) .100
$$

where $\rho_{c}$ is the density of the compound electrolyte given by:

$$
\rho_{c}=\rho_{1} V_{1}+\rho_{2} V_{2}
$$

and $\rho_{i}$ and $V_{i}(i=1,2)$ are the crystallographic densities and volume fractions of phases 1 (LSGM) and 2 (8YSZ), respectively, in weight percent.

Microstructure features were observed by field emission gun scanning electron microscopy, FEG-SEM (Inspect F50, FEI). In this case, the powders were spread out onto carbon tape and sintered pellets were polished with diamond pastes $(15,6$ and $1 \mu \mathrm{m})$ and thermally etched at $100^{\circ} \mathrm{C}$ below the sintering temperature. The average grain size was estimated by the intercept method ${ }^{13}$.

Ionic conductivity measurements were carried out in an impedance analyzer (4192A, Hewlett Packard) in the $5 \mathrm{~Hz}$ to $13 \mathrm{MHz}$ frequency range with $200 \mathrm{mV}$ of applied voltage. Silver paste was applied onto parallel surfaces of sintered pellets and fired at $400^{\circ} \mathrm{C}$ to remove the organic binder.

\section{Results and Discussion}

Figure 1 shows powder XRD patterns collected during preparation of LSGM. The diffraction pattern of the starting mixture shows, as expected, the main peaks of lanthanum (1) and gallium (2) oxides. After the first calcination step at $1250^{\circ} \mathrm{C}$ for $4 \mathrm{~h}$, the LSGM phase (indicated by *) has already been formed. Nevertheless, as the reaction among the several starting materials is incomplete, some diffraction peaks of impurity phases are detected, especially $\mathrm{La}_{4} \mathrm{Ga}_{2} \mathrm{O}_{9}$ (3), $\mathrm{LaSrGa}_{3} \mathrm{O}_{7}$ (4) and $\mathrm{LaSrGaO}_{4}$ (5). The subsequent steps of calcination and attrition milling promoted a decrease in the relative fraction of undesired phases, such that the final powder mixture consists primarily of the LSGM phase and minor amounts (less than $5 \%$, estimated by intensity ratios) of the usually observed impurity phases.

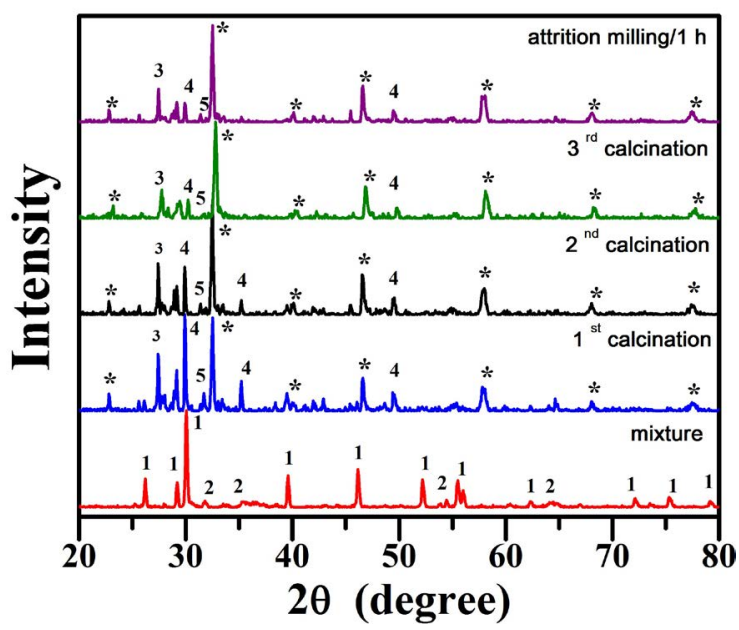

Figure 1. XRD patterns of the starting powder mixture and after calcination $\left(1250{ }^{\circ} \mathrm{C}\right.$ for $\left.4 \mathrm{~h}\right)$ and attrition milling. $1-\mathrm{La}_{2} \mathrm{O}_{3}$, $2-\mathrm{Ga}_{2} \mathrm{O}_{3}, 3-\mathrm{La}_{4} \mathrm{Ga}_{2} \mathrm{O}_{9}, 4-\mathrm{LaSrGa}_{3} \mathrm{O}_{7}$ and $5-\mathrm{LaSrGaO}_{4}$. The orthorhombic phase of LSGM is indicated by *.

FEG-SEM micrographs of (a) as-prepared LSGM, (b) 8YSZ commercial powder and (c) 8 YSZ with 20 wt.\% LSGM are depicted in Figure 2. The LSGM powder (Figure 2a) prepared by solid state reaction is characterized by agglomerated particles of irregular shape. Commercial 8YSZ (Figure 2b) are spherical granules resulting from the spray drying process in the production route. The mixture of 8 YSZ and LSGM (Figure 2c) consists of porous agglomerates, their size increasing with increasing 8 YSZ content. These agglomerates seems to be soft, they break during the conformation step, leading to high density pellets after sintering at $1450^{\circ} \mathrm{C}$, as summarized in Table 1 .

The relative density of pure LSGM sintered at $1350^{\circ} \mathrm{C}$ is $93.5 \%$. In contrast, for higher sintering temperatures the density is $99 \%$. The relative density of compound electrolytes decreases for increasing $8 \mathrm{YSZ}$ addition. At $1450^{\circ} \mathrm{C}$, the density is near full for all pellets except for those with $20 \mathrm{wt} \%$ 8YSZ. The density of common impurity phases was not taken into account in these calculations, because their total amount is relatively low. Hereafter only results on pellets sintered at $1450^{\circ} \mathrm{C}$ will be shown.

XRD patterns of as-sintered pellets are shown in Figure 3. The plots on the left exhibit the entire angular range of XRD measurements, whereas those on the right are enlarged views of the $24-32^{\circ}$ range, where the main diffraction peaks of impurity phases are detected. 8 YSZ and LSGM display the characteristic cubic fluorite-type and orthorhombic perovskite-type crystalline structures, respectively. Surprisingly, addition of 8YSZ to LSGM promotes phase stabilization, and for $10 \mathrm{wt} \% \%$ addition, the XRD pattern resembles that of a single phase material. Increasing the fraction of $8 Y$ YZ to $20 \mathrm{wt} . \%$ a new phase attributed to lanthanum zirconate, $\mathrm{La}_{2} \mathrm{Zr}_{2} \mathrm{O}_{7}$ with pyrochlore structure was detected revealing a strong interaction among the individual elements of the compound electrolyte. 

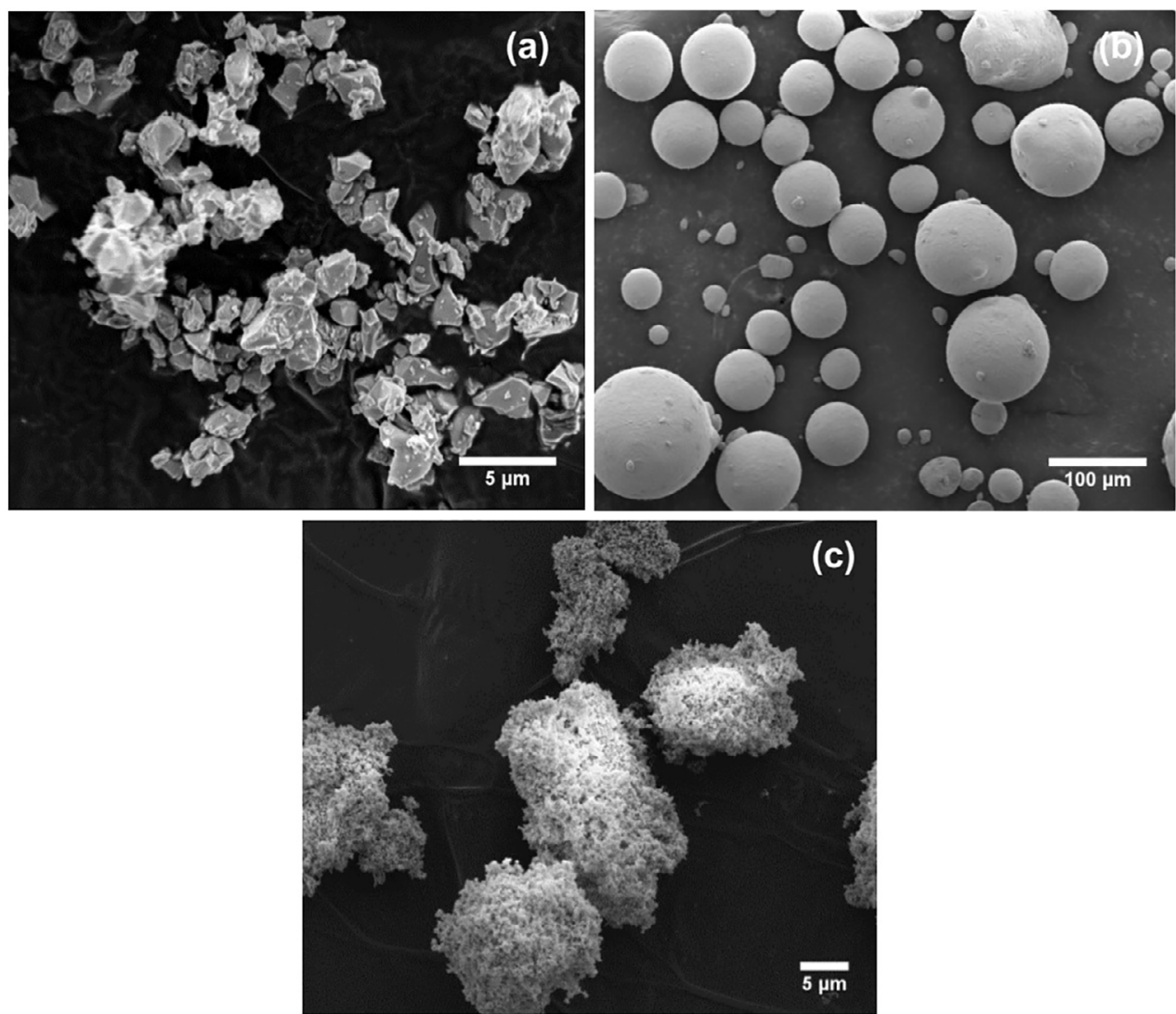

Figure 2. FEG-SEM micrographs of (a) LSGM, (b) 8 YSZ and (c) 20 wt. $\% 8$ YSZ added to LSGM.
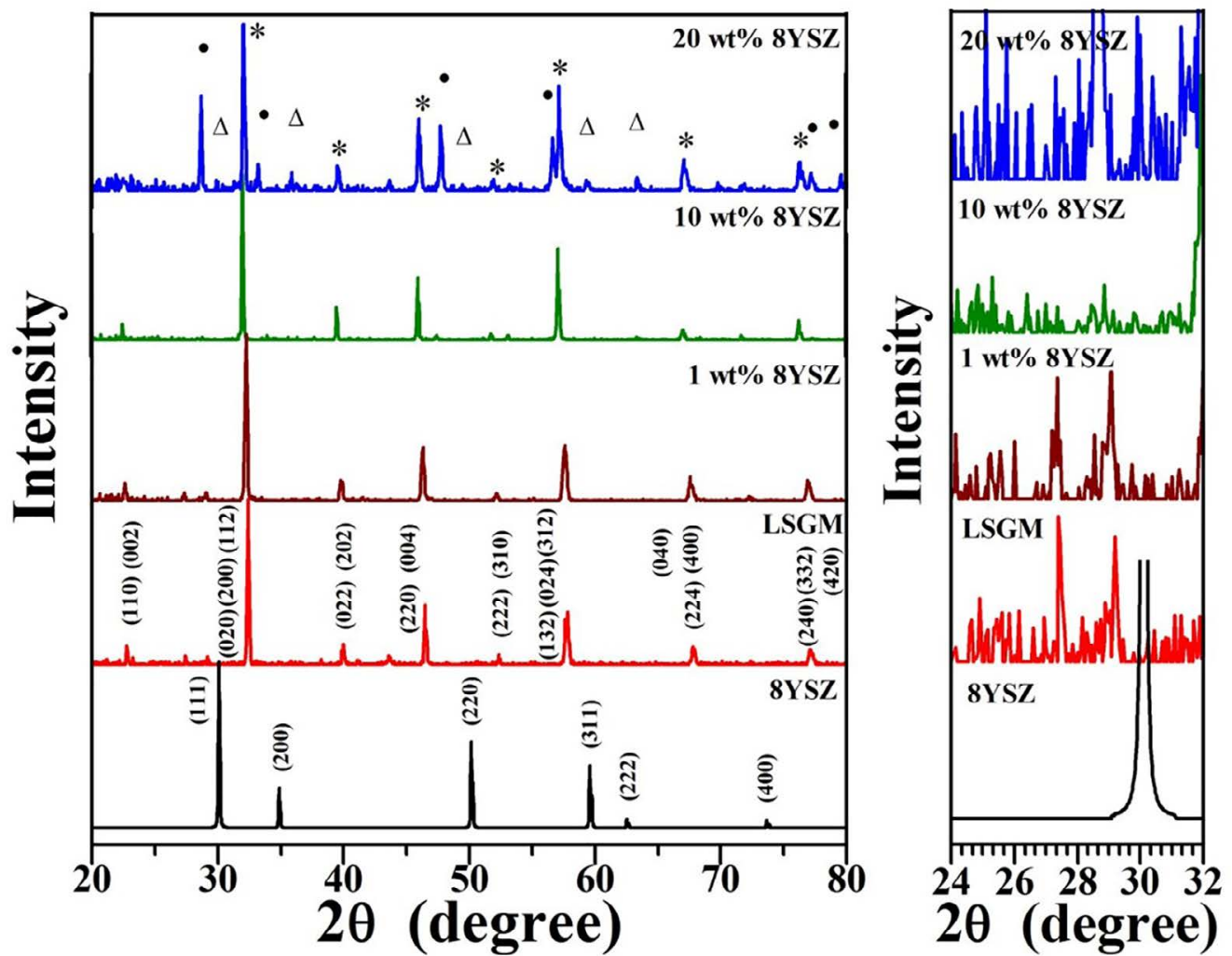

Figure 3. XRD patterns of LSGM, $8 \mathrm{YSZ}$ and compound electrolytes after sintering at $1450{ }^{\circ} \mathrm{C}$ for $4 \mathrm{~h} .{ }^{*}$ - $\mathrm{LSGM}, \Delta-8 \mathrm{YSZ}$ and $\bullet-\mathrm{La}_{2} \mathrm{Zr}_{2} \mathrm{O}_{7}$. 
Table 1. Values of relative density $\left(\rho_{\mathrm{r}}\right)$ for LSGM pellets containing different amounts of $8 \mathrm{YSZ}$ and sintered at several temperatures for $4 \mathrm{~h}$.

\begin{tabular}{ccc}
\hline Sintering Temperature $\left({ }^{\circ} \mathrm{C}\right)$ & $8 Y S Z(w t . \%)$ & $\rho_{\mathrm{r}}(\%)$ \\
\hline 1350 & 0 & 93.5 \\
1350 & 1 & 96.0 \\
1350 & 10 & 71.0 \\
1350 & 20 & 74.6 \\
1400 & 0 & $\approx 99$ \\
1400 & 1 & $\approx 99$ \\
1400 & 10 & 85.5 \\
1400 & 20 & 85.0 \\
1450 & 0 & $\approx 99$ \\
1450 & 1 & $\approx 99$ \\
1450 & 10 & $\approx 99$ \\
1450 & 20 & 92.3 \\
\hline
\end{tabular}

Figure 4 shows FEG-SEM micrographs of polished and thermally etched sintered pellets of (a) LSGM, (b) 8YSZ, (c) LSGM+10 wt. \% 8YSZ, and (d) LSGM+20 wt.\% 8YSZ. The main microstructure features of LSGM (Figure $4 \mathrm{a}$ ) are polygonal grains with negligible porosity. Grains with smooth and rough surfaces are observed. Similar features are found for 8 YSZ (Figure 4b) pellets with grains with smooth surfaces. This difference in the texture of LSGM grains has already been reported and attributed to different factors, such as the presence of stacking faults, or to changes in the microstructure occurring during thermal etching or during cooling down from the sintering temperature ${ }^{14-17}$. The compound electrolytes exhibit similar features as those of base ceramic materials, except by microregions with a different (dark) contrast suggesting the emerging of a new phase. These findings are in general agreement with XRD results, which revealed the lanthanum zirconate as a second phase in these ceramics. The FEG-SEM results shows inequivocally that this secondary phase had already been formed with $10 \mathrm{wt} . \% 8 \mathrm{YSZ}$ addition to LSGM. Values of the average grain size of sintered pellets are summarized in Table 2.
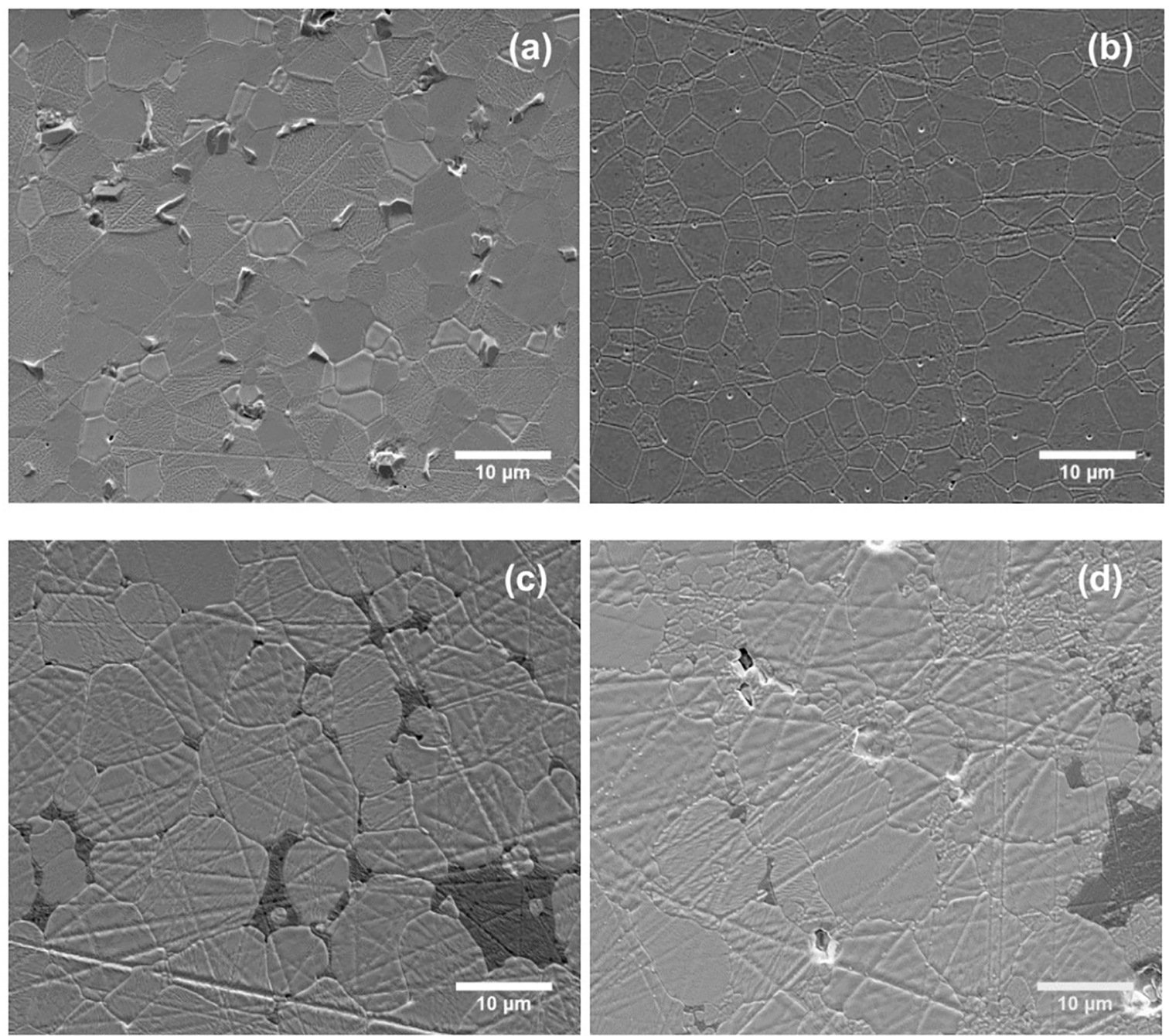

Figure 4. FEG-SEM micrographs of (a) LSGM, (b) 8YSZ, (c) 10 wt.\% and (d) 20 wt.\% 8YSZ added to LSGM. 
Table 2. Values of average grain size and apparent activation energy $\left(\mathrm{E}_{\mathrm{a}}\right)$ for conduction of solid electrolytes sintered at $1450{ }^{\circ} \mathrm{C}$ for $4 \mathrm{~h}$.

\begin{tabular}{ccc}
\hline $8 \mathrm{YSZ}($ wt.\%) & Average grain size $(\mu \mathrm{m})$ & $\mathrm{E}_{\mathrm{a}}(\mathrm{eV})$ \\
\hline 0 & 6.35 & 0.99 \\
1 & 7.15 & 0.98 \\
10 & 11.48 & 0.93 \\
20 & 13.30 & 1.02 \\
\hline
\end{tabular}

The average grain size of LSGM is $6.35 \mu \mathrm{m}$, which is close to that of pure $8 \mathrm{YSZ}(5.55 \mu \mathrm{m})$ sintered under the same experimental conditions. Addition of 8YSZ to LSGM produced substantial grain growth, suggesting a strong interaction between these two solid electrolytes during sintering. The grain growth process is fast up to $10 \mathrm{wt} . \% 8 \mathrm{YSZ}$ and slows down for higher additive contents.

Impedance spectroscopy diagrams recorded at $268^{\circ} \mathrm{C}$ are shown in Figure 5. The real (Z') and the imaginary (Z') components of the total impedance were normalized for pellet dimensions for comparison purpose. Numbers in these plots are the relaxation frequencies. As usual for oxide-ion conductors, the whole diagram consists of decentralized arcs, ascribed to the resistive and capacitive effects of grains, grain boundaries and the electrolyte/electrode interface ${ }^{18}$. The impedance diagrams of pure LSGM and LSGM with $1 \mathrm{wt} . \% 8 \mathrm{YSZ}$ show two arcs at high and low frequencies. The arc attributed to the grain boundaries, which is usually detected at intermediate frequencies $(\sim 1 \mathrm{kHz})$, becomes significant in polycrystalline ceramics only for grain sizes lower than $5 \mu \mathrm{m}^{19}$. Then, only the grain or bulk component of the total conductivity was analyzed. The bulk resistivity of LSGM with $1 \mathrm{wt} . \% 8 \mathrm{YSZ}$ is slightly lower than that of pure LSGM. In contrast, addition of $10 \mathrm{wt} . \% 8$ YSZ resulted in a huge increase of the bulk resistivity.

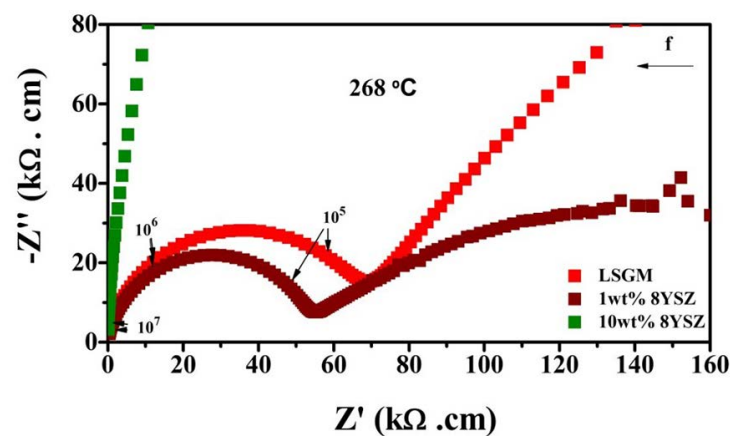

Figure 5. Impedance spectroscopy diagrams of pure LSGM and with 1 and $10 \mathrm{wt} . \%$ addition of $8 \mathrm{YSZ}$. Temperature of measurement $=268^{\circ} \mathrm{C}$.

Arrhenius plots of the bulk conductivity of sintered pellets are depicted in Figure 6. The straight lines are the fitting of experimental points. Indeed, the addition of $1 \mathrm{wt} . \% 8 \mathrm{YSZ}$ to LSGM resulted in a small increase of the bulk conductivity of LSGM. The apparent activation energy values determined by curve fitting are summarized in Table 2 .

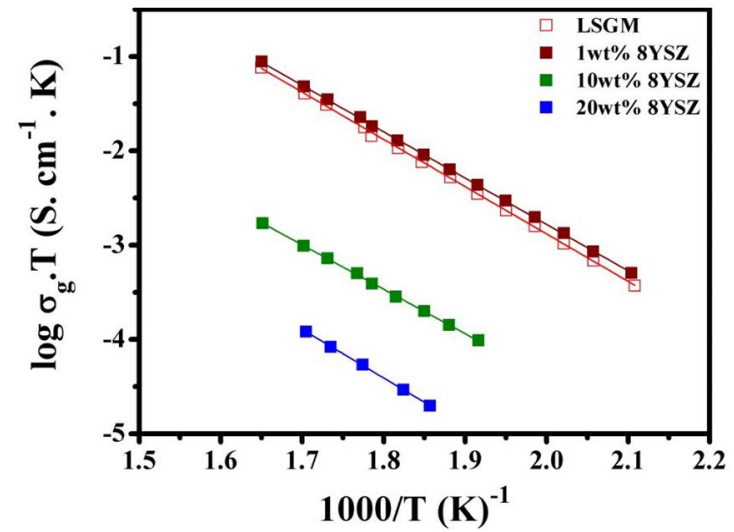

Figure 6. Arrhenius plots of the bulk conductivity of solid electrolytes sintered at $1450{ }^{\circ} \mathrm{C}$ for $4 \mathrm{~h}$.

Addition of up to $10 \mathrm{wt} . \% 8 \mathrm{YSZ}$ to LSGM promoted decrease of the apparent activation energy for the bulk conductivity.

The grain size (Table 2) does not influence the bulk conductivity of polycrystalline solid electrolytes. In contrast, the density or porosity (Table 1) may reduce drastically the ionic conductivity. The specimen with $20 \mathrm{wt} . \% 8 \mathrm{YSZ}$, for example, exhibits the lowest bulk conductivity (Fig. 6), which is a consequence of the difference in the conductivity of both electrolytes, and the presence of the insulating phase $\left(\mathrm{La}_{2} \mathrm{Zr}_{2} \mathrm{O}_{7}\right)$, and because of its lower density compared to other specimens.

The overall results suggest that adding 8 YSZ to LSGM may improve some properties. From a microstructural point of view, additions up to $10 \mathrm{wt} . \% 8 \mathrm{YSZ}$ promotes better phase stability, by decreasing the impurity phases contents. Moreover, $1 \mathrm{wt} . \% 8 \mathrm{YSZ}$ added to LSGM results in a small and unexpected (the ionic conductivity of 8YSZ is known to be much smaller than that of LSGM) increase of the bulk conductivity of LSGM. The reason as to why this occurs is unclear, but it seems to be related to a decrease in the apparent activation energy for conduction, related to improved stoichiometry of LSGM as a consequence of reduction of impurity phase contents. Interaction between the two solid electrolytes takes place during sintering, giving rise to lanthanum zirconate as secondary phase. That phase with pyrochlore structure has lower ionic conductivity than both LSGM and $8 \mathrm{YSZ}^{20}$.

\section{Conclusions}

Compound electrolytes constituted by mixtures of doped lanthanum gallate and yttria-stabilized zirconia were successfully prepared by solid state reaction. Additions of up to $10 \mathrm{wt} . \% 8 \mathrm{YSZ}$ reduce the fraction of impurity phases in the LSGM. Interaction of the two electrolytes gives rise to lanthanum zirconate as secondary phase for additions of at least $10 \mathrm{wt} . \% 8 \mathrm{YSZ}$. A small increase of the bulk conductivity of LSGM was observed for $1 \mathrm{wt} . \% 8 \mathrm{YSZ}$ addition, with a decrease of the apparent activation energy for conduction. 


\section{Acknowledgements}

The authors acknowledge FAPESP (2013/07296-2), CNPq (305889/2018-4), CAPES (Finance code 001) and CNEN for financial supports.

\section{References}

1. Minh NQ. Ceramic Fuel Cells. Journal of the American Ceramic Society. 1993;76(3):563-588.

2. Gao Z, Mogni LV, Miller EC, Railsback JG, Barnett SA. A perspective on low-temperature solid oxide fuel cells. Energy \& Environmental Science. 2016;9(5):1602-1644.

3. Ishihara $\mathrm{T}$, Matsuda $\mathrm{H}$, Takita $\mathrm{Y}$. Doped $\mathrm{LaGaO}_{3}$ Perovskite Type Oxide as a New Oxide Ionic Conductor. Journal of the American Chemical Society. 1994;116(9):3801-3803.

4. Feng M, Goodenough JB. A superior oxide-ion electrolyte. European Journal of Solid State and Inorganic Chemistry. 1994;31:663-672.

5. Yokokawa H, Sakai N, Horita T, Yamaji K, Brito ME. Solid Oxide Electrolytes for High Temperature Fuel Cells. Electrochemistry. 2005;73(1):20-30.

6. Morales M, Roa JJ, Tartaj J, Segarra M. A review of doped lanthanum gallates as electrolytes for intermediate temperature solid oxides fuel cells: From materials processing to electrical and thermo-mechanical properties. Journal of the European Ceramic Society. 2016;36(1):1-16.

7. Huang PN, Petric A. Superior Oxygen Ion Conductivity of Lanthanum Gallate Doped with Strontium and Magnesium. Journal of the Electrochemical Society. 1996;143(5):16441648.

8. Liu N, Shi M, Wang C, Yuan YP, Majewski P, Aldinger F. Microstructure and ionic conductivity of Sr- and Mg-doped $\mathrm{LaGaO}_{3}$. Journal of Materials Science. 2006;41(13):4205-4213.

9. Jo SH, Muralidharan P, Kim DK. Electrical conductivity studies on the LSGM-CGO composite electrolytes. Journal of Alloys and Compounds. 2010;491(1-2):416-419.
10. Raghvendra, Singh RK, Singh P. Electrical conductivity of LSGM-YSZ composite materials synthesized via coprecipitation route. Journal of Materials Science. 2014;49(16):5571-5578.

11. Wu YC, Lee MJ, Li X. Analysis of the microstructure and physical properties of $\mathrm{La}_{0.85} \mathrm{Sr}_{0.15} \mathrm{Ga}_{0.8} \mathrm{Mg}_{0.2} \mathrm{O}_{2.825}$ and $\mathrm{Ce}_{0.85} \mathrm{Sm}_{0.15} \mathrm{O}_{1.925}$ composite electrolytes used in solid oxide fuel cells. Journal of the European Ceramic Society. 2015;35(16):4485-4495.

12. Reis SL, Muccillo ENS. Preparation of dense $\mathrm{La}_{0.9} \mathrm{Sr}_{0.1} \mathrm{Ga}_{0.8} \mathrm{Mg}_{0.2} \mathrm{O}_{3-\delta}$ with high ionic conductivity by solid-state synthesis. Ionics. 2018;24(6):1693-1700.

13. Mendelson MI. Average Grain Size in Polycrystalline Ceramics. Journal of the American Ceramic Society. 1969;52(8):443-446.

14. Zhao X, Li X, Xu N, Huang K. Beneficial effects of Mg-excess in $\mathrm{La}_{1-\mathrm{x}} \mathrm{Sr}_{\mathrm{x}} \mathrm{Ga}_{1-\mathrm{y}} \mathrm{Mg}_{\mathrm{y}+\mathrm{z}} \mathrm{O}_{3-\delta}$ as solid electrolyte. Solid State Ionics. 2012;214:56-61.

15. Wu YC, Lee MZ. Properties and microstructural analysis of $\mathrm{La}_{1-\mathrm{x}} \mathrm{Sr}_{\mathrm{x}} \mathrm{Ga}_{1-\mathrm{y}} \mathrm{Mg}_{\mathrm{y}} \mathrm{O}_{3-\delta}$ solid electrolyte. Ceramics International. 2013;39(8):9331-9341.

16. Stevenson JW, Armstrong TR, Pederson LR, Li J, Lewinsohn CA, Baskaran S. Effect of A-site cation nonstoichiometry on the properties of doped lanthanum gallate. Solid State Ionics. 1998;113-115:571-583.

17. Oncel C, Ozkaya B, Gulgun MA. X-ray single phase LSGM at $1350{ }^{\circ} \mathrm{C}$. Journal of the European Ceramic Society. 2007;27(23):599-604.

18. Bauerle JE. Study of solid electrolyte polarization by a complex admittance method. Journal of Physics and Chemistry of Solids. 1969;30(12):2657-2670.

19. Kleitz M, Bernard H, Fernandez E, Schouler E. Impedance spectroscopy and electrical resistance measurements on stabilized zirconia. In: Heuer AH, Hobbs LW, eds. Science and Technology of Zirconia. Westerville: The American Ceramic Society; 1981. p. 310-336.

20. Mahato N, Banerjee A, Gupta A, Omar S, Balani K. Progress in material selection for solid oxide fuel cell technology: A review. Progress in Materials Science. 2015;72:141-337. 